\title{
Regulatory Barriers and Entry in
}

\section{Developing Economies*}

\author{
John Bennett, Brunel University\$ \\ Saul Estrin, London Business School
}

March 7, 2006

\begin{abstract}
We model entry by entrepreneurs into new markets in developing economies with regulatory barriers in the form of licence fees and bureaucratic delay. Because laissez faire leads to 'excessive' entry, a licence fee can increase welfare by discouraging entry. However, in the presence of a licence fee, bureaucratic delay creates a strategic opportunity, which can result in both greater entry by first movers and a higher steady-state number of firms. Delay also leads to speculation, with entrepreneurs taking out licences to obtain the option of immediate entry if they later observe the industry to be profitable enough.
\end{abstract}

Keywords: Entry, Entry Barriers, Developing Economy.

JEL Classification: L50, O14

\footnotetext{
* Estrin is Adecco Professor of Business and Society. We thank the Department for International Development for supporting this research under DFID/ESCOR project number R7844. Earlier versions of this paper were presented at the European Bank for Reconstruction and Development, London, February 2005; the Latin American and Caribbean Economic Association Annual Congress, Paris, October, 2005; and the ASSA meeting, Boston, January 2006. We are grateful to the participants, and particular, Dan Berkowitz and Hadi Esfahani, for their comments. The usual disclaimer applies.

${ }^{\$}$ Corresponding author: Centre for Economic Development and Institutions (CEDI), Brunel University, Uxbridge, UB8 3PH, United Kingdom; tel +44 (0)1895 266649; fax +44 (0)1895 269770; email john.bennett@brunel.ac.uk
} 


\section{Introduction}

Since Schumpeter (1934) a substantial theoretical and empirical literature has emerged to analyse the process of new firm entry in developed economies (Jovanovic, 1982; Evans, 1987; Dunn, Roberts and Samuelson, 1989; and Ericson and Pakes 1995). ${ }^{1}$ However, while the significance of entry for developing economies is recognized (Tybout, 2000), there has been little formal modeling of the issues relating to entry in these economies, and of the associated problems posed by their weaker institutional structures. In this paper we analyze the process of entry into an entirely new industry in a developing economy, focusing on the impact for welfare of regulatory intervention. Our model builds on the work of Hausmann and Rodrik (2003), who explore how small open economies learn about what they are good at producing. We find that the appropriate policy for enhancing entry rates is more complex than simply to ensure the operation of 'good institutions.' The factors inhibiting entry work in subtle ways, and, in particular, the interactions between early and later entrants need to be taken into account.

Since de Soto (1990), it has been argued that regulatory entry barriers are a major factor causing low entry rates in developing economies, with negative implications for output and employment growth (see Roberts and Tybout, 1996, and Tybout, 2000). Djankov et al. (2002) provide comparative data on the regulations

\footnotetext{
${ }^{1}$ See also Geroski (1995) and Caves (1998).
} 
affecting entry in 85 countries. These include the number of procedures required to start a firm (which, between countries, varies from 2 to 21 ), the minimum time for start up (from 2 to 152 days), and the official cost (from $0.5 \%$ to $560 \%$ of per capita GDP). The average costs of entry are found to be rather high in most countries, and countries with heavier entry regulations are found to have larger unofficial economies and higher levels of corruption.

There is also evidence that entry regulations have a negative effect on the rate of formation of new enterprises. Scarpetta et al. (2002) find that the rate of entry of small and medium enterprises is negatively related to the number of regulations, especially those in the product and labour markets (see also Desai, Gompers and Lerner, 2003). Klapper, Laeven and Rajan (2004) explore the impact on entry barriers by looking at the interactions between country-specific and industry-specific variables. The main country characteristic used in the regressions is the cost of fulfilling bureaucratic requirements to register a company. They find that, for industries with high entry rates in the US, relative entry is disproportionately lower in countries in which entry costs are higher. They conclude that entry regulations do hinder entry, especially in industries that should 'naturally' have higher rates of entry.

Our model addresses the initial level of entry by entrepreneurs into the new industry in a developing economy and the steady-state solution obtaining after 
any subsequent entry or exit. We examine regulatory intervention in the forms of a licence fee and of bureaucratic delay. Such interventions are not uniformly damaging; for example, the imposition of a small licence fee is found to raise welfare because it discourages entry. A delay between the application for a licence and its receipt can increase the number of entrants, because of the strategic advantage derived from early entry. After specifying the characteristics of a new industry in Section 2, we go on in Section 3 to examine the benchmark case of socially optimal pattern of entry and exit in a developing economy. In Section 4 we consider the free-market solution with and without licence fees, the latter being denoted 'laissez faire.' When the fee is zero, entry is found to be excessive because each entrant ignores that its entry involves unnecessary duplication of sunk learning costs. Since an entry barrier in the form of a licence fee has a negative effect on both initial entry and the steady-state number of firms, a sufficiently small licence fee actually raises welfare. However, because it is a single policy tool, it cannot induce both socially optimal initial entry and the socially optimal steady-state number of firms simultaneously. We also find that weaker property rights, if associated with greater spillovers, can eventually lead to more entry and a higher level of production.

In Section 5 we introduce a time lag between the payment of a licence fee and the granting of a licence. We show that, in equilibrium, entrepreneurs choose to divide into three groups. One group pays the fee immediately, entering after the 
required lag, while a second group never buys the licence. Those in the third group choose to 'speculate' on a licence, buying the licence early, before the profitability of early entrants is revealed. Depending on the level of profitability that is later revealed, some or all of the speculators may enter without further delay, while any remaining speculators never enter. Interestingly, the option of speculation causes entrepreneurs to eschew delaying the decision as to whether to purchase a licence until profitability is revealed. Thus, our model provides a rationale for the phenomenon of more licences being issued (even with a positive cost) than firms entering. If the entry fee is small, the existence of delay raises the number of initial entrants because of the strategic advantage they are given over later entrants. If the entry fee is large enough, however, entry by first movers is discouraged. Section 6 concludes.

\section{The Industry}

We model the process of entry in a developing economy, whose characteristics are described primarily in terms of factor supply constraints and institutional deficiencies relative to more developed economies. This is because we assume that, while innovation in developing countries will typically be through the imitation of existing production methods in developed economies, such technology is not common knowledge. Rather, the transfer of technology to new economic and institutional 
environments requires adaptations, and there is an associated uncertainty about the future of profitability of the new ventures (see Hausmann and Rodrik, 2003). Hence entrepreneurs set up firms in a particular 'new' industry, the profitability of which is initially unknown.

We therefore consider a new modern-sector industry, with no incumbent firms at time $t=0$. Any entrepreneur may innovate, setting up a firm to enter the industry and produce at $t=1$. Though information on the supply of entrepreneurs is limited, studies of self-employment and latent entrepreneurship (see, e.g., Blanchflower, Oswald and Stutzer, 2001) do not suggest that entrepreneurship is a function of income per capita (see also Casson et al., 2006). Thus, the supply of potential entrepreneurs is assumed large relative to the number that actually set up firms in the industry in equilibrium. ${ }^{2}$ Entrepreneurs (and firms) are indexed $i=1,2, \ldots$

Entry by entrepreneur $i$ at $t=1$ requires a sunk cost $k$ in learning and setting up in the industry. As is common in developing economies (see Djankov et al., 2002), it also requires the payment of a fee $f \geq 0$ for a licence. If $k$ and $f$ are incurred at $t=1$, the firm will also need to employ a unit of skilled labour in any

\footnotetext{
${ }^{2}$ At any time $t$ there are more potential entrants than the market can sustain. The question therefore arises of how the entry of only some of these potential entrants is co-ordinated. We assume that there is some small exogenous asymmetry between potential entrants that allows entry to take place only up to the point at which the present value of the expected profit stream for the marginal entrant is zero. An alternative approach would be to model a mixed-strategy equilibrium, but this would add complexity, and Levin and Peck (2003) have shown that this approach can generate some rather implausible results.
} 
period $t$ in order to produce. The output of any active firm $i$ at time $t$ is

$$
y_{t}^{i}=\theta+\beta n_{t}, \quad \beta \geq 0, \quad t=1,2, \ldots
$$

At $t=1, \theta$ is stochastic, being uniform over $[0,2 \Theta]$; but, given that at least one entrepreneur sinks the learning cost $k$ at $t=1$, the value of $\theta$ becomes common knowledge at $t=2$. In conjunction with the other parameter values, $\theta$ represents the profitability of the industry in the country concerned. $\theta$ captures the idea that, although the industry may exist in other countries, its suitability to local conditions and institutions can only be discovered by experimentation. Note that $\theta$ is not firm-specific. Unlike in Jovanovic (1982) or Ericson and Pakes (1995), entrepreneurs do not learn about their own abilities; rather, they learn about their environment.

Apart from $\theta$ at $t=1$, the values of all variables and parameters in the model are common knowledge. The total number of firms in the industry at $t$ is denoted by $n_{t}$, and $\beta$ is a parameter. The term $\beta n_{t}$ is included to allow for a network externality, which is increasing in the number of firms in the industry. For simplicity, output demand is assumed perfectly elastic. Output price is fixed at unity, and so $y_{t}$ can also be interpreted as revenue.

In our model, the new industry is assumed to employ only skilled labour, and we represent supply constraints by an increasing supply price. The wage for this 
labour, $w_{t}$ per unit at time $t$, is

$$
w_{t}=\delta+\alpha n_{t}, \quad \delta, \alpha>0, \quad t=1,2, \ldots
$$

For stability, we assume that $\alpha-\beta \equiv \Omega>0$.

Any number of entrepreneurs can enter the industry at any time. For a first mover (that is, an entrant at $t=1$ ) $\theta$ is stochastic. Then, for a potential second mover (that is, an entrant at $t=2$ ) the value of $\theta$ is known. We assume, however, that although the production function (1), including the value of $\theta$, can be observed by a second mover, methods of production can be only partially observed. A second mover must therefore sink the learning/set-up cost $(1-\gamma) k$, where $0 \geq$ $\gamma \geq 1$ is the spillover from the knowledge that a first mover acquires at $t=1$. These observations concerning second movers also apply to potential entrants at $t=3,4, \ldots$

Since no information becomes available after $\theta$ is revealed at the beginning of $t=2$, there will be no reason for a firm to prefer to enter or exit in later periods, rather than at the beginning of $t=2$. Therefore, for $t \geq 3, n_{t}=n_{2}, y_{t}^{i}=y_{2}^{i}$, and $w_{t}=w_{2}$. Writing $\pi_{t}^{i}$ and $\pi_{t}^{j}$ for the respective profits at time $t$ of a first mover $i$ 
and a second mover $j$, we have

$$
\begin{aligned}
& \pi_{1}^{i}=\theta-\delta-\Omega n_{1}-k-f ; \quad \pi_{t}^{i}=\theta-\delta-\Omega n_{2}, \quad t=2,3, \ldots \\
& \pi_{2}^{j}=\theta-\delta-\Omega n_{2}-(1-\gamma) k-f ; \quad \pi_{t}^{j}=\theta-\delta-\Omega n_{2}, \quad t=3,4, \ldots
\end{aligned}
$$

The present value, at $t=2$, of first mover $i$ 's profit stream, if it stays in production, is

$$
V_{2}^{i}=\frac{1}{1-\sigma}\left(\theta-\delta-\Omega n_{2}\right)
$$

where $\sigma \in(0,1)$ is a discount factor. The present value, at $t=2$, of second mover j's profit stream is

$$
V_{2}^{j}=\frac{1}{1-\sigma}\left(\theta-\delta-\Omega n_{2}\right)-K
$$

where

$$
K \equiv(1-\gamma) k+f
$$

In each case that follows, we examine the entry by first movers, the subsequent pattern of entry and exit, and the steady-state number of firms $n^{*}$ in the industry, which is the number of firms that enter, but do not exit (i.e., the number of firms in the industry at $t=2,3, \ldots)$. 


\section{The Social Optimum}

Since output demand is perfectly elastic, we measure social welfare by the expected present value of the aggregate profit stream when the licence fee $f$ set at zero. Since there is no uncertainty after the value of $\theta$ is revealed (between $t=1$ and $t=2$ ), the optimum number of firms is the same at $t=3,4, \ldots$ as at $t=2$. Hence, we consider only the socially optimal values of $n_{1}$ and $n_{2}$, and we solve the model by backward induction. At $t=2, n_{2}$ is chosen to maximize the present value $V_{2}$ of the aggregate profit stream, given the realization of $\theta$. Taking this into account, at $t=1, n_{1}$ is chosen to maximize the present value, $V_{2}$, of the expected aggregate profit stream.

At $t=2$ the number of entrants $n_{1}$ from $t=1$ is given. Let $n_{1}^{\prime}$ denote the number of first movers (entrants at $t=1$ ) that stay in production at $t=2,3, \ldots$ and let $m_{2}$ denote the number of second movers (new entrants at $t=2$ ). The socially optimal behaviour at $t=2$ depends on the realization of $\theta$. From (4) and (5), the present value, at $t=2$, of the aggregate profit stream, with $f=0$, is

$$
n_{1}^{\prime} V_{2}^{i}+m_{2} V_{2}^{j} \equiv V_{2}=\frac{1}{1-\sigma}\left(n_{1}^{\prime}+m_{2}\right)\left[\theta-\delta-\Omega\left(n_{1}^{\prime}+m_{2}\right)\right]-(1-\gamma) k m_{2}
$$

At $t=2, n_{1}^{\prime}$ and $m_{2}$ are chosen to maximize $V_{2}$. 
From (7), $d V_{2} / d m_{2}$ for $n_{1}^{\prime}=n_{1}$ is given by ${ }^{3}$

$$
\left(\frac{d V_{2}}{d m_{2}}\right)_{n_{1}^{\prime}=n_{1}}=\frac{1}{1-\sigma}\left[\theta-\delta-2 \Omega\left(n_{1}+m_{2}\right)\right]-(1-\gamma) k
$$

This is equal to zero, for zero entry $m_{2}$ at $t=2$, if

$$
\theta=\delta+2 \Omega n_{1}+(1-\sigma)(1-\gamma) k \equiv \tilde{\theta}\left(n_{1}\right)
$$

If $\theta>\tilde{\theta}\left(n_{1}\right)$, then $V_{2}$ is raised by entry at $t=2$. A positive value of $m_{2}$ should be set such that $d V_{2} / d m_{2}=0$ for $n_{1}^{\prime}=n_{1}$; that is, from (8),

$$
n_{2}=n_{1}+m_{2}=\frac{1}{2 \Omega}[\theta-\delta-(1-\sigma)(1-\gamma) k] .
$$

However, if $\theta \leq \tilde{\theta}\left(n_{1}\right), m_{2}$ should be zero: there should be no entry by second movers. In this case we must consider how much exit, if any, there should be by first movers.

Note from (7) that, setting $m_{2}=0$ and then differentiating, $d V_{2} / d n_{1}^{\prime}=0$ if

$$
\theta=2 \Omega n_{1}+\delta \equiv \theta^{\prime}\left(n_{1}\right)
$$

If $\theta \geq \theta^{\prime}\left(n_{1}\right)$, there will be no exit in the socially optimal solution. Hence, for

\footnotetext{
${ }^{3}$ Throughout, we approximate by treating the number of firms as continuous.
} 
$\tilde{\theta}\left(n_{1}\right) \geq \theta \geq \theta^{\prime}\left(n_{1}\right)$, the social optimal number of firms at $t=2$ is $n_{1}$. But if $\theta<\theta^{\prime}\left(n_{1}\right)$, there will be exit, and, provided $\theta \geq \delta$, the number of survivors $n_{1}^{\prime}$ will satisfy (11); that is,

$$
n_{1}^{\prime}=\frac{\theta-\delta}{2 \Omega} \equiv \tilde{n}_{1}^{\prime}
$$

In this case the amount of exit will be $n_{1}-\tilde{n}_{1}^{\prime}$.

Finally, if $\theta<\delta$ all $n_{1}$ first movers will exit at $t=2$, and there will be no further entry.

We now derive the socially optimal entry of firms at $t=1$, taking into account what we have found about socially optimal behaviour at $t=2$. Let $V_{1}$ denote the present value, at $t=1$, of the aggregate expected profit stream, and assume, for now, that $\tilde{\theta}\left(n_{1}\right)<2 \Theta$. Then $V_{1}$ can be split into four components. The first is the aggregate profit earned in $t=1$ by the $n_{1}$ first movers, and the other three components relate to expected profits at $t=2,3, \ldots$ for each of the three ranges of $\theta$ specified in the previous sub-section. Thus, we obtain

$$
\begin{aligned}
2 \Theta V_{1}= & n_{1} \int_{0}^{2 \Theta}\left(\theta-\delta-\Omega n_{1}-k\right) d \theta+ \\
& \int_{\tilde{\theta}}^{2 \Theta}\left\{\frac{\sigma}{1-\sigma}\left[\theta-\delta-\Omega\left(n_{1}+m_{2}\right)\right]\left(n_{1}+m_{2}\right)-\sigma(1-\gamma) k m_{2}\right\} d \theta+ \\
& \frac{\sigma n_{1}}{1-\sigma} \int_{\theta^{\prime}}^{\tilde{\theta}}\left(\theta-\delta-\Omega n_{1}\right) d \theta+\frac{\sigma \tilde{n}_{1}^{\prime}}{1-\sigma} \int_{\delta}^{\theta^{\prime}}\left(\theta-\delta-\Omega \tilde{n}_{1}^{\prime}\right) d \theta
\end{aligned}
$$


Let $n_{1}^{\text {opt }}$ denote the value of $n_{1}$ at which $d V_{1} / d n_{1}=0$. From (13), it is found that

$$
n_{1}^{o p t}=\frac{\Theta\{\Theta-\delta-[1-\sigma(1-\gamma)] k\}-\sigma(1-\gamma) k\left[\frac{3}{4} \delta+\frac{1}{2}(1-\gamma)(1-\sigma) k\right]}{\left[2 \Theta+\frac{3}{2} \sigma(1-\gamma) k\right] \Omega} .
$$

Since $d V_{1}^{2} / d n_{1}^{2}<0, n_{1}=n_{1}^{o p t}$ is socially optimal. Note that $n_{1}^{o p t}$ is increasing in $\Theta$, and decreasing in $\delta, k$, and $\Omega$, while $d n_{1}^{o p t} / d \sigma$ and $d n_{1}^{o p t} / d \gamma$ may take either sign.

We rest our analysis on the assumption that $n_{1}^{\text {opt }}>0$, that is, with a benevolent social planner, the industry would be started. A necessary condition for this inequality to hold is that, in (14),

$$
\Theta-\delta-[1-\sigma(1-\gamma)] k>0
$$

This implies that in the range $\theta \in[0,2 \Theta]$ the higher values yield a positive righthand side of (10). Also, it implies that $\tilde{\theta}\left(n_{1}\right)<2 \Theta$, as we have already assumed, the range covered by the second integral in (13) being positive. ${ }^{4}$ If the value of $\Theta$ is reduced, the inequality $\tilde{\theta}\left(n_{1}\right)<2 \Theta$ is not violated because the value of $n_{1}^{\text {opt }}$ falls sufficiently quickly.

Figure 1 depicts this solution. The value of $\theta$ is shown on the horizontal

\footnotetext{
4 Setting $n_{1}=n_{1}^{*}$, we obtain $2 \Theta-\tilde{\theta}\left(n_{1}\right)=\left(2 \Theta^{2}+z\right) /[2 \Theta+3 \sigma(1-\gamma) k / 2]$, where $z=$ $\Theta k[3 \sigma(1-\gamma) / 2+\gamma]-\sigma(1-\sigma) k^{2}(1-\gamma)^{2} / 4$. Thus, sufficient for $2 \Theta-\tilde{\theta}\left(n_{1}\right)>0$ is that $z \geq 0$, i.e., $\Theta / k \geq\left[\sigma(1-\sigma) k^{2}(1-\gamma)^{2} / 4\right] /[3 \sigma(1-\gamma) / 2+\gamma]$. But, from (14), given that $n_{1}^{*}>0$, we have that $\Theta-\delta-[1-\sigma(1-\gamma)] k>0$, i.e., that $\Theta / k>1-\sigma(1-\gamma)$. Combining these inequalities, sufficient for $2 \Theta-\tilde{\theta}\left(n_{1}\right)>0$ is that $1-\sigma(1-\gamma) \geq\left[\sigma(1-\sigma) k^{2}(1-\gamma)^{2} / 4\right] /[3 \sigma(1-\gamma) / 2+\gamma]$, which reduces to $\sigma(1-\gamma)[3-(1-\gamma)(5 \sigma-1) / 2]+2 \gamma[1-\sigma(1-\gamma)] \geq 0$. Since both terms [.] in this inequality are positive, $2 \Theta-\tilde{\theta}\left(n_{1}\right)>0$.
} 
axis and the number of firms $n_{t}$ at time $t$ on the vertical axis. The steady-state number of firms in the social optimum, $n^{* o p t}$, is shown by the thick line segments. Of the two upward-sloping segments, the one on the left is $n_{1}=(\theta-\delta) / 2 \Omega$, the value $n^{* o p t}$ would take if sunk cost $K$ were zero, ${ }^{5}$ and the one on the right is $n_{1}=[\theta-\delta-(1-\sigma)(1-\gamma) k] / 2 \Omega$, the value $n^{* o p t}$ would take if sunk cost $K$ were $(1-\sigma)(1-\gamma) k$. The vertical difference between $n^{* o p t}$ and $n_{1}^{\text {opt }}$ for a given value of $\theta$ is the amount of entry or exit at $t=2$.

[Figure 1]

\section{Market Equilibrium}

We now assume that entrepreneurs make decisions freely about whether to enter or exit. In this section we assume that although a licence may be required, there is no delay in receiving it.

We solve the model by backward induction, and, again, since the solution is the same at $t=3,4, \ldots$ as at $t=2$, we begin with $t=2$. We assume that parameter values are such that there is positive entry at $t=1$ in the solution. ${ }^{6}$

The value of $n_{2}$ depends on the range of values within which $\theta$ falls. Four cases

\footnotetext{
${ }^{5}$ Because at least one firm has to enter for our analysis to obtain, we start this line just above the $\theta$-axis.

${ }^{6}$ As we shall see, this is implied by our assumption that $n_{1}^{\text {opt }}>0$. If all firms find it unprofitable to enter at $t=1$, they will also find it unprofitable at $t=2$, and the industry will not be established.
} 
can be distinguished.

Case (a) All $n_{1}$ first movers would exit because even one of them alone in the industry would make a loss at $t=2$. From (3), this occurs if

$$
\theta<\delta+\Omega \equiv \theta_{a}
$$

If (16) holds, all first movers exit; and since second movers are at a cost disadvantage relative to first movers (still having to incur a set-up cost), there are is no entry by second movers.

Case (b) In this range $\theta \geq \theta_{a}$, and so some of the $n_{1}$ first movers remain in the industry at $t=2$, while some exit. If all $n_{1}$ first movers were to remain in the industry the $n_{1}$-th would make a loss, i.e., from (3),

$$
\theta<\delta+\Omega n_{1} \equiv \theta_{b}\left(n_{1}\right)
$$

Thus, $\theta \in\left[\theta_{a}, \theta_{b}\right)$. Because, at $t=2$, a potential second mover is at a cost disadvantage relative to any first mover, there is no entry by second movers. The number of firms $n_{2}$ in this case is such that $V_{2}^{i}=0$, so that, from (4),

$$
n_{2}=\frac{\theta-\delta}{\Omega}>0 \text { for } \theta \in\left(\theta_{a}, \theta_{b}\right]
$$

Case (c) If $\theta \geq \theta_{b}$ all first movers remain in the industry at $t=2$, but $\theta$ is not 
so great as to induce entry by second movers. From (5), $V_{2}^{j}$ is decreasing in $n_{2}$. Thus, if $V_{2}^{j} \leq 0$ for $n_{2}=n_{1}$, there will be no second movers. This condition can be written

$$
\theta \leq \delta+\Omega n_{1}+(1-\sigma) K \equiv \theta_{c}\left(n_{1}\right)
$$

When $\theta \in\left[\theta_{b}, \theta_{c}\right), n_{2}$ is independent of parameter values.

Case (d) If $\theta \in\left(\theta_{c}, 2 \Theta\right]$ the first movers will all remain in the industry at $t=2$ and there will be entry by second movers until $V_{2}^{j}=0$. Hence, from (5),

$$
n_{2}=\frac{1}{\Omega}[\theta-\delta-(1-\sigma) K] \equiv \hat{n}_{2}
$$

At $t=1$ firm $n_{1}$ is the marginal firm among those that enter. Writing $\pi_{t}^{n_{1}}$ for its profit at time $t$, and taking into account the four cases for possible draws of $\theta$, the expected present value of this firm's profit stream is

$$
V_{1}^{n_{1}}\left(n_{1}\right)=\frac{1}{2 \Theta}\left\{\int_{0}^{2 \Theta} \pi_{1}^{n_{1}}\left(n_{1}\right) d \theta+\frac{\sigma}{1-\sigma}\left[\int_{\theta_{b}}^{\theta_{c}} \pi_{2}^{n_{1}}\left(n_{1}\right) d \theta+\int_{\theta_{c}}^{2 \Theta} \pi_{2}^{n_{1}}\left(\hat{n}_{2}\right) d \theta\right]\right\} .
$$

Here, the term in parentheses (.) after each $\pi_{t}^{n_{1}}$ denotes the number of firms in the industry in the time period considered. The first integral covers profit at $t=1$, while the second and third integrals relate to profit at $t=2$ in Cases (c) and (d) respectively. (If Case (a) or (b) applied, firm $n_{1}$ would exit, and so no term is 
specified.) $\pi_{1}^{n_{1}}($.$) and \pi_{2}^{n_{1}}($.$) are given by (4), while \hat{n}_{2}$ is given by (20). Thus,

$$
V_{1}^{n_{1}}\left(n_{1}\right)=\left(\Theta-\delta-\Omega n_{1}-k-f\right)-\frac{1}{4 \Theta} \sigma(1-\sigma) K^{2}+\sigma K\left(1-\frac{\delta+\Omega n_{1}}{2 \Theta}\right)
$$

From (22), $d V_{1}^{n_{1}}\left(n_{1}\right) / d n_{1}<0 . n_{1}$ adjusts such that, in equilibrium, $V_{1}^{n_{1}}\left(n_{1}\right)=$ 0 , the solution being $n_{1}=\hat{n}_{1}(f)$, where

$$
\hat{n}_{1}(f)=\frac{2 \Theta-\delta}{\Omega}-\frac{4 \Theta(\Theta+k+f)+\sigma(1-\sigma) K^{2}}{2 \Omega(2 \Theta+\sigma K)} .
$$

From (20) and (23), we can find, for Case (d), how many second movers will enter. Denoting this number by $\hat{m}_{2}(f)=\hat{n}_{2}(f)-\hat{n}_{1}(f)$, we obtain

$$
\hat{m}_{2}(f)=\frac{4 \Theta(\theta-\Theta+\gamma k)+\sigma K[2 \theta-(1-\sigma) K]}{2 \Omega(2 \Theta+\sigma K)} \text { for } \theta \in\left(\theta_{c}, 2 \Theta\right] .
$$

Let $n^{* m}(f)$ denote the steady-state number of firms in the market solution for licence fee $f$. Since by $t=2$ all uncertainty is resolved, $n^{* m}(f)=n_{2}$. The value of $n^{* m}(f)$ depends on which of cases (a)-(d) obtains.

The effects of variation in parameter values on $\hat{n}_{1}(f)$ and $n^{* m}(f)$ are easily obtained. Since there are four cases of the latter, and, in general, the results are intuitively as might be expected, for brevity, we do not discuss them. ${ }^{7}$ In

\footnotetext{
${ }^{7} \hat{n}_{1}$ is increasing in $\sigma$ and $\beta$, and decreasing in $\alpha, \delta, \gamma, k$ and $f$. In case (a) $n^{* m}=0$. In Case (b) $n^{* m}$ is increasing in $\beta$, decreasing in $\alpha$ and $\delta$, and independent of $\sigma, \gamma, k$ and $f$. In Case (c) $n^{* m}=\hat{n}_{1}$. In Case (d), $n^{* m}$ is increasing in $\sigma, \beta$ and $\gamma$, and decreasing in $\alpha, \delta, k$ and $f$.
} 
particular, $d \hat{n}_{1}(f) / d f<0$ and, for $n^{* m}(f)>0, d n^{* m}(f) / d f<0$, results that we return to below. However, one other result is worth commenting on - the effect of variation in the spillover parameter $\gamma$. Using (6) and (20), we obtain the following result.

Lemma 1 A higher value of the spillover parameter $\gamma$ is associated with a smaller entry of first movers, but, provided $\theta$ is high enough for second movers to enter, this effect is more than outweighed (after a one-period lag) by the greater entry of second movers.

This has the interesting implication that, if weaker property rights are associated with greater levels of spillover, they will cause a lower level of entry initially, but competitive pressures can lead eventually to more entry in total, with a larger number of new firms and a higher level of output. Pressures in developing economies to strengthen intellectual property rights, for example via the World Trade Organization, in so far as they affect the level of spillovers in the domestic market, may have the perverse effect of reducing the total number of firms and production. 


\subsection{Laissez Faire, Licences, and Sub-Optimality}

Setting $f=0$, we obtain the laissez-faire solution. From (23),

$$
\hat{n}_{1}(0)=\frac{\Theta\{\Theta-\delta-[1-\sigma(1-\gamma)] k\}-\sigma(1-\gamma) k\left[\frac{1}{2} \delta+\frac{1}{4}(1-\gamma)(1-\sigma) k\right]}{[\Theta+\sigma(1-\gamma) k] \Omega} .
$$

Comparing (25) with (14), it is immediately see that $\hat{n}_{1}(0)$ exceeds $n_{1}^{\text {opt }}$, the entry at $t=1$ in the social optimum. ${ }^{8}$

To compare the steady-state number of firms $n^{* m}(f)$ for $f=0$ with the social optimum, we draw the diagram corresponding, for laissez faire, to Figure 1. This is done in Figure 2, where the thick line depicts the laissez-faire case and the broken line depicts the social optimum. Period-1 entry in the laissez-faire case is labelled $n_{1}^{m}(0)$. From (10) (12), (18) and (20), the slopes of the upward sloping portions of $n^{* m}(0)$ are half the slopes of the corresponding portions for $n^{* o p t}$. We cannot tell, unconditionally, whether each discontinuity for the laissez-faire line $n^{* m}(0)$ is to the left or right of of the corresponding discontinuity for the social optimum $n^{* o p t}$; but the critical features of the figure are that, for each line, for one firm to stay in the industry we must have $\theta=\delta+\Omega$, while for any $\theta$ greater than this, $n^{* m}(0)>n^{* o p t}$.

[Figure 2]

\footnotetext{
${ }^{8}$ From (25) and (14), if $k=0$ laissez faire results in social optimal entry at $t=1$. Similarly, if $k=0$ laissez faire results in optimal entry/exit at $t=2$. Thus, it is the duplication of sunk costs that leads to overentry in the text.
} 
Our first proposition summarizes the main conclusions for laissez-faire.

Proposition 1 Laissez faire leads to excessive entry at $t=1: \hat{n}_{1}(0)>n_{1}^{\text {opt }}$; and, provided $\theta>\delta+\Omega$, there is is an excessive number of firms in the laissez-faire steady state $\left(n^{* m}(0)>n^{* o p t}\right)$.

For $n_{1}>1$, laissez-faire leads to excessive first-mover entry and to too many licences in the steady state because each entrepreneur fails to take into account that he or she is sinking costs for learning to an extent that is unnecessary from a social point of view.

Finally, we consider the effect of the licence fee on the market solution; that is, we compare the equilibrium for $f=0$ with that for $f>0$. The effects are shown in Figure 3, where the zero-licence fee case is shown by the broken line, and the positive-licence fee case is shown by the thick line. From (23), $d \hat{n}_{1} / d f<0$, while from (20), a greater $f$ is associated with a lower $n_{2}$ for $\theta \in\left(\theta_{c}, 2 \Theta\right]$; also, from (17) and (19), $d \theta_{b} / d f<0$ and $d \theta_{c} / d f<0$, respectively. However, from (18), if $\theta<\theta_{b}, n_{2}$ is independent of the value of $f:$ within this range of $\theta, n_{2}<n_{1}$ and so the value of $n_{1}$ (which does depend on $f$ ) is irrelevant, and for firms making the decision about whether to stay in the industry at $t=2, f$ is a by-gone. This gives our the next lemma.

[Figure 3] 
Lemma 2 A positive licence fee reduces the number of first movers and, for $\theta>$ $\theta_{b}\left(\hat{n}_{1}\right)$, reduces the steady-state number of firms.

Since laissez faire is associated with excessive entry, the introduction of a positive licence fee can raise welfare. ${ }^{9}$ The level of $f$ that maximizes social welfare, subject to the constraint that entry is unregulated, can be derived, but the formula is not simple enough to yield clear insights. ${ }^{10}$ However, as $f$ is raised past this optimal level, welfare falls along with entry.

\section{Delay and Speculation}

In the formulation above, the licence fee $f$ plays almost the same role as the learning cost $k$, the only difference being that while all firms pay the same fee, the existence of a spillover causes second movers, though not first movers, to pay only a portion of $k$. We now suppose, however, that there is a one-period delay between paying the licence fee and getting the licence. Thus, we suppose that first movers pay the licence fee at $t=0$ and begin production at $t=1$. As above, the realization of $\theta$ is observed between $t=1$ and $t=2$. With this amendment to the model, one possibility is for other firms to wait to observe the realization of $\theta$ and then, if the realization is favourable, pay the fee $f$ immediately. Thus, $f$ would be

\footnotetext{
${ }^{9}$ However, if $k=0$ the introduction of a licence fee necessarily reduces welfare.

10 It is found that social optimal value of $f$ satisfies $\left[2 \Theta(\Theta+k+f-\Omega)+\sigma(1-\sigma) K^{2} / 2-\hat{n}_{1} \Omega\right] d \hat{n}_{1} / d f-2 \hat{n}_{1} \Theta=0$.
} 
paid at the beginning of $t=2$ and then entry by second movers would occur at the beginning of $t=3$, with the learning cost $(1-\gamma) k$ then being incurred.

However, entry may take a different form. An entrepreneur may decide to 'speculate,' applying for a licence, but not producing before the realization of $\theta$, and then only going into production if the realization is sufficiently favourable. Thus, the entrepreneur may pay the fee at the beginning of $t=1$, and then either begin production at the beginning of $t=2$ or not begin production at all. We can therefore now distinguish three types of entry: by first movers, by speculators and by 'later movers' (entrepreneurs who wait to see the realization of $\theta$ before possibly paying $f$ ).

At $t=2$ a first mover has a cost advantage $(1-\gamma) k$ over a speculator, and so, if a speculator enters, we know that all first movers are remaining in the industry. At $t=2$ and $t=3$ a speculator has the cost advantages of $f$ and $(1-\gamma) k$ over a later mover, and so, if any later movers enter, we know that all speculators are staying in. To solve the model, we begin by disregarding later movers entirely, considering only first movers and speculators. (We shall then show that no entrepreneurs will choose to be later movers.)

Suppose that $s_{1}$ entrepreneurs buy licences at $t=1$. For any one of these 
speculators, $h$, if he or she then enters at $t=2$, profit is

$$
\begin{aligned}
& \pi_{2}^{h}=\theta-\delta-\Omega n_{2}-(1-\gamma) k ; \\
& \pi_{t}^{h}=\theta-\delta-\Omega n_{3}, \quad t=3,4, \ldots
\end{aligned}
$$

And, at $t=2$, the present value of its profit stream is

$$
V_{2}^{h}=\theta-\delta-\Omega n_{2}-(1-\gamma) k+\frac{\sigma}{1-\sigma}\left(\theta-\delta-\Omega n_{3}\right)
$$

The number of speculators that then enter at $t=2$ depends on what realization of $\theta$ occurs. The realizations can be divided into three cases.

Case (SA) If $\theta$ is low enough, $V_{2}^{h}<0$ for all $h \in\left(n_{1}, n_{1}+s_{1}\right]$, so that none of the speculators enter. Since, at $t=2$, a speculator has a cost disadvantage relative to a first-mover, the highest value of $\theta$ at which this case obtains is when all $n_{1}$ first movers would nonetheless remain in the industry. Hence, Case (SA) is defined by writing $n_{2}=n_{3}=n_{1}$ in (27) and finding the values of $\theta$ for which $V_{2}^{h}<0$, i.e.,

$$
\theta<\delta+\Omega n_{1}+(1-\sigma)(1-\gamma) k \equiv \theta_{S A}\left(n_{1}\right)
$$

Case (SB) In this range (28) is violated, and some, but not all, $s_{1}$ speculators enter. If all speculators were to enter, the least efficient would make a loss in 
present value terms; i.e., from (27),

$$
\theta<\delta+\Omega\left(n_{1}+s_{1}\right)+(1-\sigma)(1-\gamma) k \equiv \theta_{S B}\left(n_{1}\right)
$$

The number of firms adjusts such that in (27), $V_{2}^{h}=0$ for $h=n_{2}$, i.e.,

$$
n_{2}=\frac{1}{\Omega}[\theta-\delta-(1-\sigma)(1-\gamma) k] \equiv \hat{n}_{2}^{s}
$$

Case (SC) Here, all $s_{1}$ speculators enter; i.e., (29) is violated.

Moving back to $t=1$, we can now consider the payoff from speculation. The expected present value for the marginal speculator (the $s_{1}$-th) is

$$
V_{1}^{s_{1}}\left(n_{1}+s_{1}\right)=-f+\frac{\sigma}{2 \Theta} \int_{\theta_{S B}}^{2 \Theta}\left[\pi_{2}^{n_{1}+s_{1}}\left(n_{1}+s_{1}\right)+\frac{\sigma}{1-\sigma} \pi_{3}^{n_{1}+s_{1}}\left(n_{1}+s_{1}\right)\right] d \theta \text {. }
$$

The first term in [.] is profit including set-up cost $(1-\gamma) k$, while the second is the stream of discounted profits after the set-up cost has been incurred. Hence,

$$
V_{1}^{s_{1}}\left(n_{1}+s_{1}\right)=-f+\frac{\sigma}{\Theta(1-\sigma)}\left(\Theta-\frac{\theta_{S B}}{2}\right)^{2} .
$$

From (29) and (31), $d V_{1}^{s_{1}}\left(n_{1}+s_{1}\right) / d s_{1}<0 . s_{1}$ adjusts such that, in equilibrium, 
$V_{1}^{s_{1}}\left(n_{1}+s_{1}\right)=0$, that is, $(29)$ and $(31)$,

$$
n_{1}+s_{1}=\frac{1}{\Omega}\left\{2 \Theta-\delta-(1-\sigma)(1-\gamma) k-2\left[\frac{\Theta(1-\sigma) f}{\sigma}\right]^{\frac{1}{2}}\right\}
$$

The ranges of $\theta$ relevant to the behavior of a first mover follow immediately from the cases already specified in this and the previous section.

Case ( $\mathrm{Fa}$ ) All first movers exit (and no speculators enter). They do this if $\theta<\theta_{a}$, as specified in (16).

Case ( Fb) Some, but not all, first movers exit (and no speculators enter). This occurs if $\theta \geq \theta_{a}$, but $\theta<\theta_{b}\left(n_{1}\right)$, as specified in (17). Note that since the value of $n_{1}$ will now be different to the value taken in the absence of delay, the value of $\theta_{b}\left(n_{1}\right)$ will also differ. $n_{2}$ is now given by (18).

Case $(F c)$ All first movers stay in production, but still no speculators enter. In this case $\theta \geq \theta_{b}\left(n_{1}\right)$, but $\theta<\theta_{S A}\left(n_{1}\right)$, where $\theta_{S A}\left(n_{1}\right)$ is given by (28).

Case $(F d)$ All first movers stay in production and some, but not all, speculators enter. This occurs if $\theta \geq \theta_{S A}\left(n_{1}\right)$, but $\theta<\theta_{S B}\left(n_{1}\right)$, where $\theta_{S B}\left(n_{1}\right)$ is given by (29). $n_{2}$ is now given by (30).

Case $(F e)$ All speculators enter. This happens if $\theta \geq \theta_{S B}\left(n_{1}\right)$, the number of firms $n_{1}+s_{1}$ being given by (32).

Given these ranges, the present value, measured from $t=0$, of the expected 
profit stream for the marginal first mover is

$$
\begin{aligned}
V_{0}^{n_{1}}\left(n_{1}\right)= & -f+\frac{\sigma}{2 \Theta} \int_{0}^{2 \Theta} \pi_{1}^{n_{1}}\left(n_{1}\right) d \theta+ \\
& \frac{\sigma^{2}}{1-\sigma} \frac{1}{2 \Theta}\left[\int_{\theta_{b}}^{\theta_{S A}} \pi_{2}^{n_{1}}\left(n_{1}\right) d \theta+\int_{\theta_{S A}}^{\theta_{S B}} \pi_{2}^{n_{1}}\left(\hat{n}_{2}^{s}\right) d \theta+\int_{\theta_{S B}}^{2 \Theta} \pi_{2}^{n_{1}}\left(n_{1}+s_{1}\right) d \theta\right],
\end{aligned}
$$

where the profit equations (3) apply, but with $f$ deleted. The first integral covers profit at $t=1$; the others cover profit at $t=2,3, \ldots$ for Cases $(\mathrm{Fc}-\mathrm{Fe})$, i.e., when the realization of $\theta$ is large enough for the marginal first mover to stay in production.

We thus find, after substituting from (32) to eliminate $s_{1}$, that

$$
\begin{aligned}
V_{0}^{n_{1}}\left(n_{1}\right)= & -(1-\sigma) f+\sigma\left(\Theta-\delta-\Omega n_{1}-k\right)-\frac{1}{4 \Theta}(1-\sigma)[\sigma(1-\gamma) k]^{2} \\
& +\sigma^{2}(1-\gamma) k\left(1-\frac{\delta+\Omega n_{1}}{2 \Theta}\right) .
\end{aligned}
$$

From (33), $d V_{0}^{n_{1}}\left(n_{1}\right) / d n_{1}<0 . n_{1}$ adjusts so that $V_{0}^{n_{1}}\left(n_{1}\right)=0$, the solution being $n_{1}=\hat{n}_{1}^{s}$, where, from $(33)$,

$$
\hat{n}_{1}^{s}=\frac{2 \Theta-\delta}{\Omega}-\frac{4 \Theta[(\Theta+k)+(1-\sigma) f / \sigma]+(1-\sigma) \sigma[K-f]^{2}}{2 \Omega[2 \Theta+\sigma(K-f)]} .
$$

We now add the possibility of later entry into the model, while still allowing for speculation. If entrepreneur $j$ pays at $t=2$ for a licence in order to begin 
production at $t=3$, the present value of his or her profit stream is

$$
V_{2}^{j}=\frac{\sigma}{1-\sigma}\left(\theta-\delta-\Omega n_{2}\right)-\sigma(1-\gamma) k-f
$$

This parallels equation (5), but incorporates additional discounting because of the time lag in receiving the licence. If $\theta$ were to be sufficiently high for such late entry to occur, an interior solution for the number of firms $n_{3}$ at $t=3$ would be characterized by $V_{2}^{n_{3}}=0$; and hence,

$$
n_{3}=\frac{1}{\Omega}\left\{\theta-\delta-(1-\sigma)\left[(1-\gamma) k+\frac{f}{\sigma}\right]\right\} .
$$

However, $n_{3}$ is the total number of firms in this case; that is, it includes the first movers and speculators, as well as later movers. Now compare (36) with (30), which gives the total number of firms in Case (SB), i.e., when the marginal speculator does not enter, though some speculators do. Because of the appearance of the term $f / \sigma, n_{3}$ in (36) is less than $n_{2}$ in (30). But when there is any late entry, our assumptions imply that all first movers have stayed in and all speculators have entered. Thus, the total number of first movers and speculators must be at least as large as in (30). We have a contradiction: (36) could only apply if the number of later movers were negative. The following lemma therefore obtains. ${ }^{11}$

\footnotetext{
11 The arguments in this section are based on licence delays when a positive fee exists. In the absence of a fee $f$ all firms would procure a licence at $t=0$ and we would effectively be back in
} 
Lemma 3 With a positive licence fee, if it is necessary to wait to be granted a licence, there is no later entry.

The up-front payment of the entry fee by speculators gives them a strategic advantage over later entrants. We can therefore disregard the possibility of later entry when there is a delay in being granted a licence. The pattern of entry is as depicted in Figure 4, where $n_{1}^{s}(f)$ is period-1 entry in the delay-case. The pattern in Figure 4 has the same general shape as that in Figure 2, except in one important respect. For $\theta \in\left[\theta_{S B}\left(n_{1}\right), 2 \Theta\right]$, the line depicting the steady-state number of firms $n^{*}$ is horizontal. This is because, for such high realizations of $\theta$, all the entrepreneurs that have speculatively bought a licence will enter, and, as we have seen, the solution to the model is such that there is no entry by later movers.

[Figure 4]

Finally, for $f>0$, we compare the solutions with and without delay. Given Lemma 3, we compare (34) with (23) to obtain the following result for first movers.

Proposition 2 There exists a critical value $f=\bar{f}(\sigma)$ such that $\hat{n}_{1}^{s} \gtreqless \hat{n}_{1}$ as $f \lesseqgtr$ $\bar{f}(\sigma)$; i.e., for $f<\bar{f}(\sigma)$ licence delay increases first-mover entry, and vice versa. Proof. From (23) and (34), using (6), we obtain $2 \Omega(2 \Theta+\sigma K)[2 \Theta+\sigma(K-$ $f)]\left(\hat{n}_{1}^{s}-\hat{n}_{1}\right) / f=A-B$, where $A=2 \Theta\left[2 \Theta\left(4 \sigma-2-\sigma^{2}\right) / \sigma-2 \sigma \gamma k+\sigma(1-\sigma)(1\right.$ the laissez-faire solution. 
$-\gamma) k]$ and $B=(1-\sigma) K\left[(2-\sigma) 2 \Theta-\sigma^{2}(1-\gamma) k\right]$. Using (15), $B>0$. Hence, using (6), we obtain $\hat{n}_{1}^{s}-\hat{n}_{1} \gtreqless 0$ as $f \lesseqgtr \bar{f}(\sigma)$, where $\bar{f}(\sigma) \equiv$ $\left.\left\{4 \Theta\left[\Theta\left(4 \sigma-2-\sigma^{2}\right) / \sigma-\sigma \gamma k-(1-\sigma)^{2}(1-\gamma)\right] k\right]+(1-\sigma)[\sigma(1-\gamma) k]^{2}\right\} / B$

Delay benefits first movers in that potential competitors (speculators) pay the fee for a licence that they may not use, and this limits their expected profit. But the cost to the potential first mover is that it must itself wait, after payment for the licence, before entry is possible. Because of the latter effect, we find that delay induces greater first-mover entry only if $f$ is sufficiently small. Indeed, we cannot rule out the possibility that $\bar{f}(\sigma)<0$, in which case licence delay necessarily causes smaller first-mover entry.

Denoting the steady-state number of firms in the presence of licence delay by $n^{* m}(f)$, we can compare this with the corresponding number $n^{* m}(f)$ without delay. The relative size of these numbers depends on the realization of $\theta$ and on parameter values, but we can make some comments by reference to Figure 4, where both are shown. Starting from $\theta=0$, and then increasing $\theta$, the steady state is at first zero in each case, and then the same upward-sloping lines apply; but then, since we cannot determine, unconditionally, in which case there is higher first-period entry, we cannot tell which steady-state number is higher (we cannot tell in which case the horizontal portion of the steady-state line in Figure 4 is higher; the figure is merely an illustration). However, for the highest values of $\theta$, provided $f$ is not so 
high as to prevent entry in the no-delay case, $n^{* m}(f)>n^{* s}(f)$, as drawn. ${ }^{12}$

\section{Concluding Comments}

Entry rates in developing economies are potentially high because numerous opportunities exist to close the technology gap with developed economies. We explore these issues in a model in which regulatory barriers that are widely observed in such economies - licence fees and bureaucratic delay - may in principle prevent these opportunities from being exploited. We find, however, that, because in this environment laissez faire leads to 'excessive' entry, low levels of regulatory barriers can in fact increase welfare. As the size of a licence fee is raised from zero, welfare first increases and then declines. We also note that, although weaker property rights discourage innovative entry, if they lead to greater spillovers, they can raise the number of firms in the steady state.

Whereas, in the absence of bureaucratic delay, a licence fee has a negative effect on both the number of first movers and on the steady-state number of firms, the combination of bureaucratic delay and a licence fee can have the opposite effects. This is because, although the time lag between application for and receipt of a licence is assumed the same for all entrepreneurs, the delay changes the balance of advantage between first and later movers. Moreover, delay opens up the option

${ }^{12}$ It is found that $\hat{n}_{2}$ in (20) is greater than $n_{1}+s_{1}$ in $(32)$ if $4 \Theta-\sigma(1-\sigma) f>0$. 
of speculative purchase of licences, not all of which are then used.

Empirical work on the impact of entry barriers (e.g., Djankov et al., 2002) has tended to assume that all barriers have negative effects on entry and that reduced entry is bad for welfare. Our analysis suggests that both of these views are too simplistic. There is evidence, however, that where bureaucratic delays are large, the number of registered firms greatly exceeds the number of active ones (see, for example, Aidis, 2005, on Russia). Our model provides an explanation of this observation. 


\section{References}

Aidis, Ruta, 2005, 'Entrepreneurship in transition economies: a review,' working paper, SSEES, University College London.

Blanchflower, David G., Andrew Oswald and Alois Stutzer, 2001, Latent entrepreneurship across nations, European Economic Review, 45, 680-691.

Casson, Mark, Bernard Yeung, Anuradha Basu and Nigel Wadeson, 2006, The Oxford Handbook of Entrepreneurship, Oxford: Oxford University Press.

Caves, Richard E., 1998, Industrial organization and new findings on the turnover and mobility of firms, Journal of Economic Literature, 36, 19471982.

Desai, Mihir, Paul Gompers and Josh Lerner, 2003, Institutions, capital constraints and entrepreneurial firm dynamics: evidence from Europe, NBER Working paper No. w10165.

De Soto, Hernando, 1990, The Other Path, New York, NY: Harper and Row.

Djankov, Simeon, Rafael La Porta, Florencio Lopez-de-Silanes and Andrei Shleifer, 2002, The regulation of entry, Quarterly Journal of Economics, 117, $1-35$.

Dunn, Timothy, Mark Roberts and Larry Samuelson, 1989, The growth and failure of US manufacturing plants, Quarterly Journal of Economics, 104, 671-698.

Ericson, Richard, and Ariel Pakes, 1995, Markov-perfect industry dynamics: a framework for empirical work, Review of Economic Studies, 62, 1, 53-82.

Evans, David S., 1987, Tests of alternative theories of firm growth, Journal of Political Economy, 95, 657-674.

Geroski, Paul, 1995, What do we know about entry? International Journal of Industrial Organization, 13, 421-440.

Hausmann, Ricardo, and Dani Rodrick, 2003, Economic development as self discovery, Journal of Development Economics, 72, 603-33.

Jovanovic, Boyan, 1982, Selection and the evolution of industry, Econometrica, 50, 649-70. 
Klapper, Leora, Luc Laeven and Raghuram G Rajan, 2004, Business environment and firm entry: evidence from international data, CEPR Discussion Paper No. 4366, April.

Levin, Dan, and James Peck, 2003, To grab the market or bide one's time: a dynamic model of entry, RAND Journal of Economics, 34, 536-556.

Roberts, Mark J., and James R. Tybout, ed., 1996, Industrial Evolution in Developing Countries: Micro Patterns of Turnover, Productivity, and Market Structure, New York: Oxford University Press.

Scarpetta, Stefano, Phillip Hemmings, Thierry Tressel and Jaejoon Woo, 2002, The role of policy and institutions for productivity and firm dynamics: evidence from micro and industry data, Economics Department, OECD, Working Paper No. 329.

Schumpeter, Joseph A.,1934, The Theory of Economic Development, Cambridge MA: Harvard University Press.

Tybout, James R., 2000, Manufacturing firms in developing countries: how well do they do, and why? Journal of Economic Literature, 38, 11-44. 
Fig 1. The Social Optimum

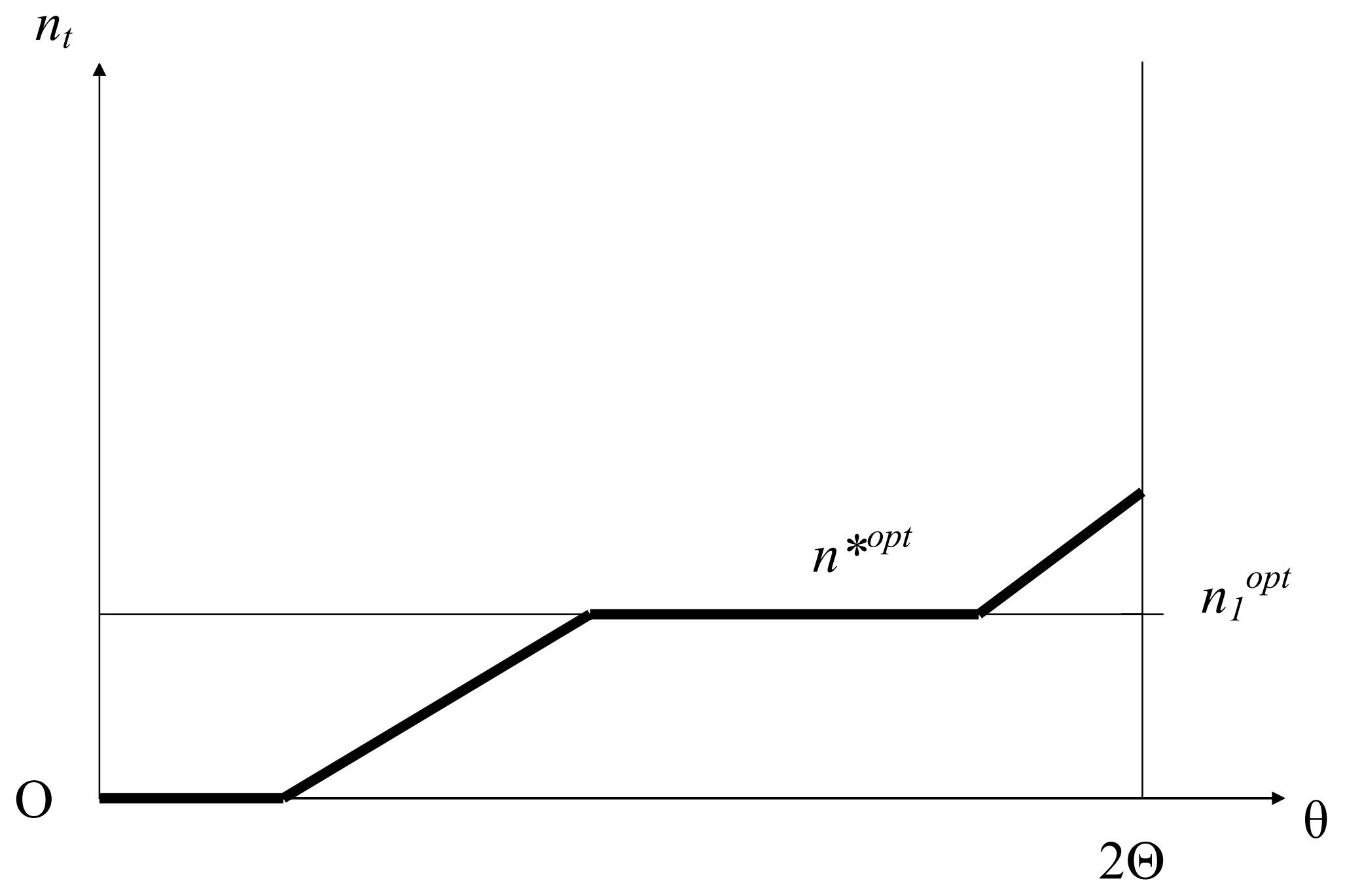


Fig 2. Laissez Faire $(f=0)$

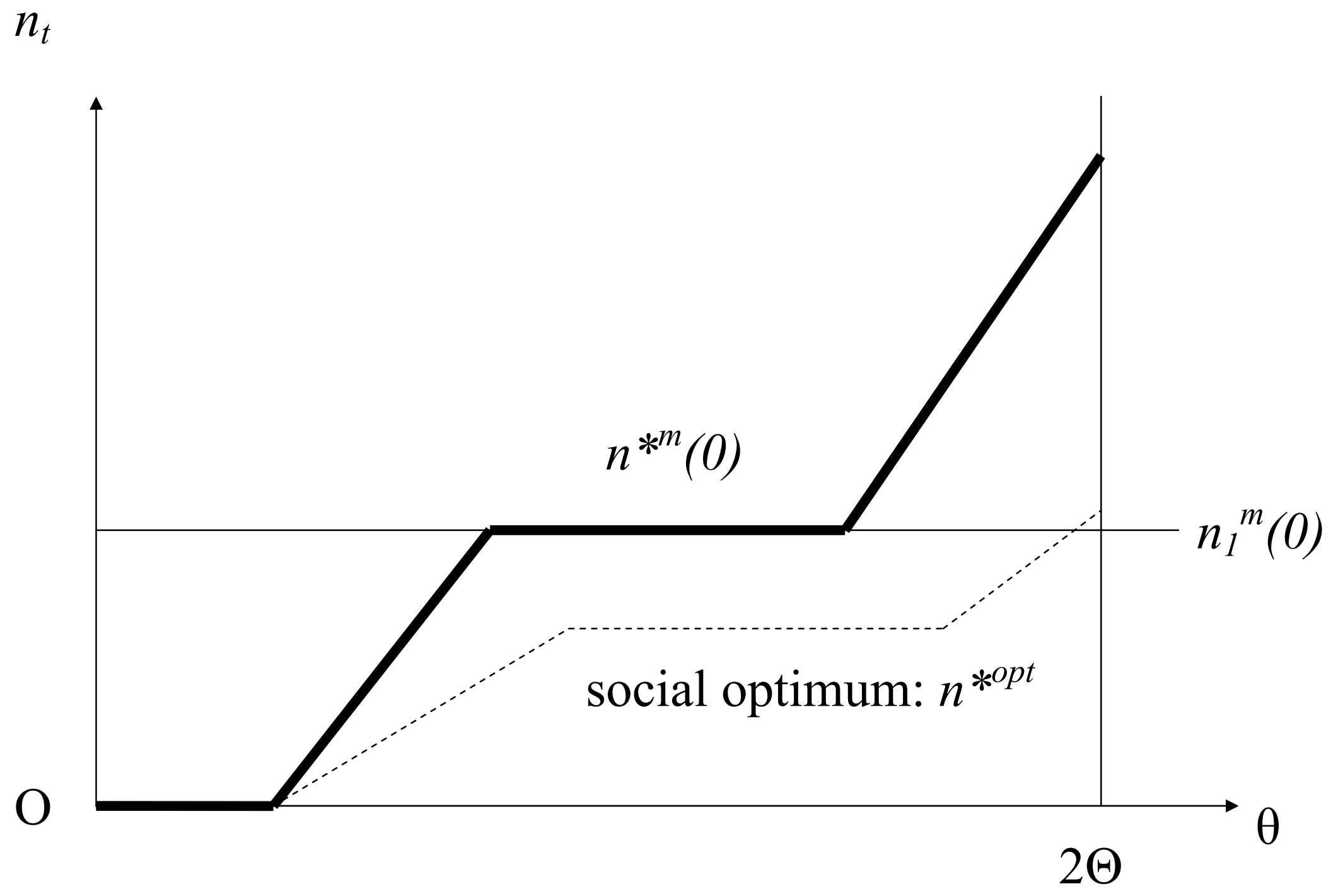


Fig 3. A Positive Licence Fee

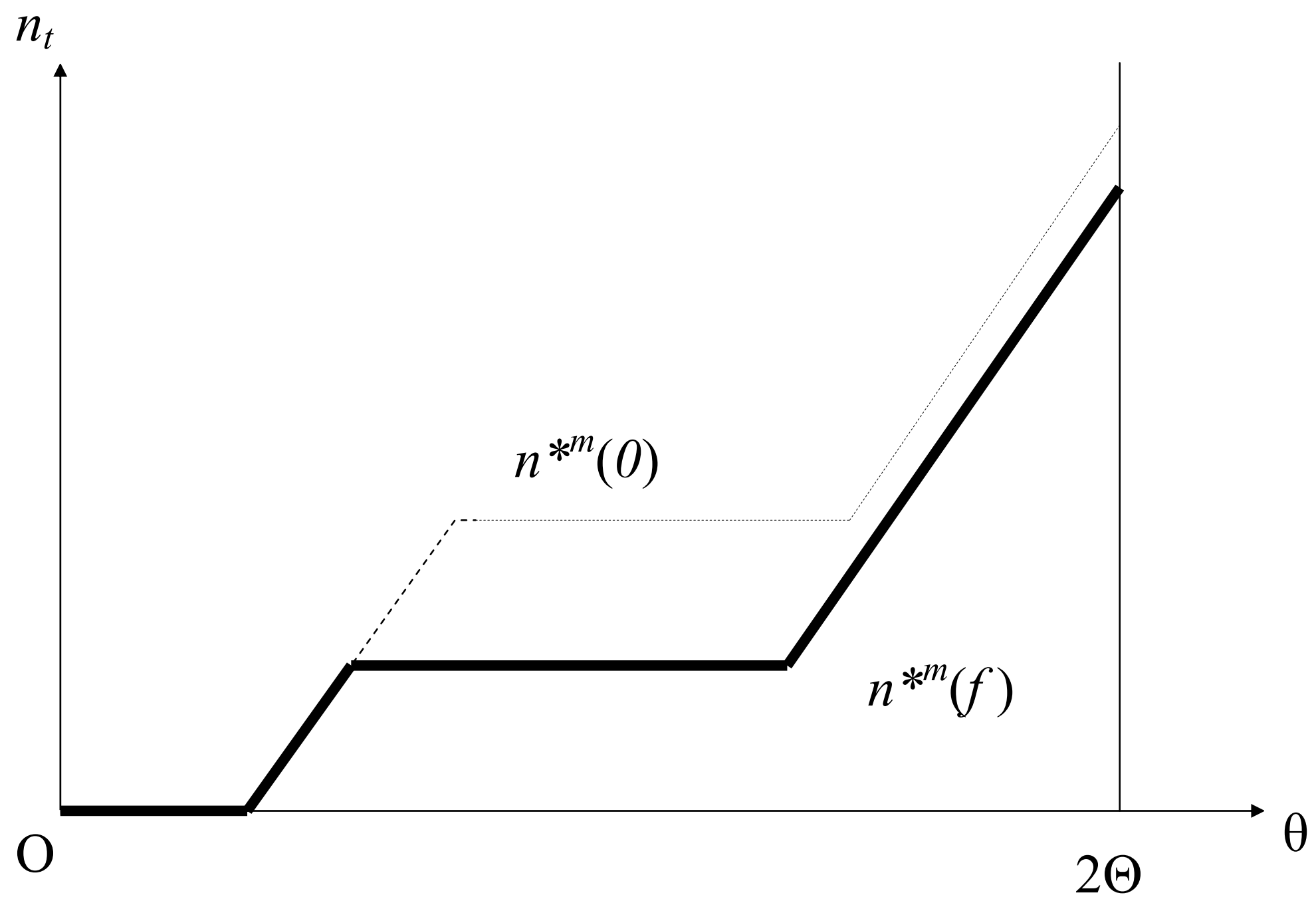


Fig 4. Speculation

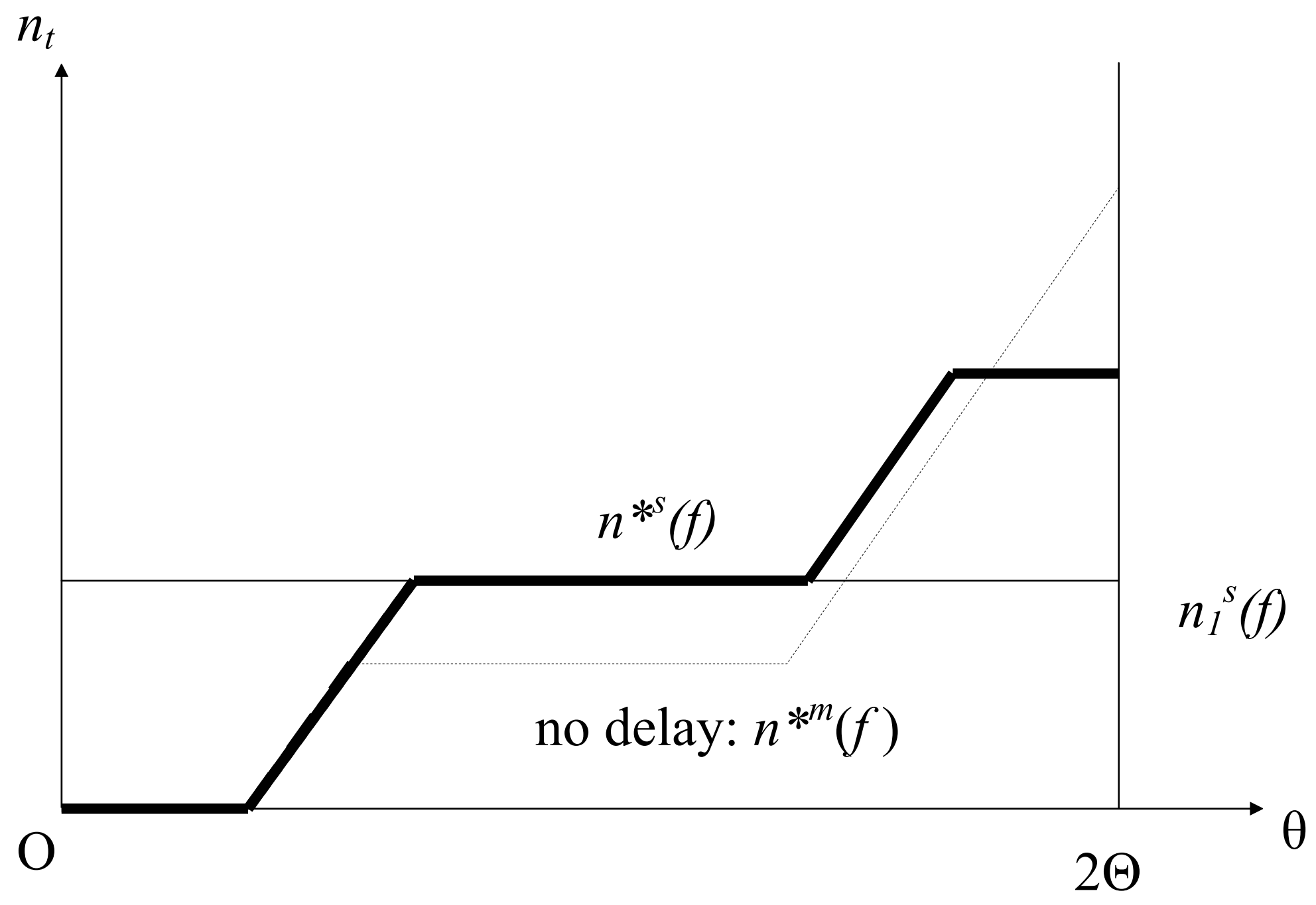

